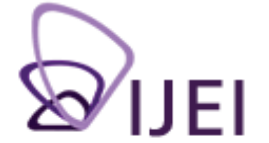

International

Journal for

Educational Integrity

\title{
Do students think what teachers think about plagiarism?
}

\author{
Tomáš Foltýnek \\ Department of Informatics, Faculty of Business and Economics, \\ Mendel University in Brno, Czech Republic \\ foltynek@pef.mendelu.cz \\ Jiři Rybička \\ Department of Informatics, Faculty of Business and Economics, \\ Mendel University in Brno, Czech Republic \\ rybicka@mendelu.cz

\section{Catherine Demoliou} \\ Life and Health Sciences Department, \\ School of Sciences, University of Nicosia, Cyprus \\ demoliou.c@uic.ac.cy
}

Keywords: plagiarism, academic integrity, higher education, policy, Europe

This paper was assessed by the Editors of the Conference Proceedings of the Plagiarism Across Europe and Beyond Conference (Brno, Czech Republic, 12-13 June 2013) as a 'best conference paper'. It was then forwarded to the IJEI for consideration. The paper has now undergone additional double-blind peer review and as a result of subsequent revisions is substantially different from the original version presented at the Czech conference.

\begin{abstract}
Preventing students' plagiarism is an important issue at Higher Education Institutions (HEI) since teachers are the ones who are primarily involved in plagiarism prevention. They have to explain to students what plagiarism is and to teach them how to avoid plagiarism. A survey conducted under the research project on the Impact of Policies for Plagiarism in Higher Education Across Europe (IPPHEAE) has collected thousands of questionnaires from both students and teachers of several HEls at various EU countries. The project addressed several research questions relating to plagiarism. This paper compares and contrasts the overall data collected on students' and teachers' attitude towards academic writing and their perception of plagiarism and plagiarism penalties as well as their knowledge of institutional policy/procedures on plagiarism. On the basis of the results obtained it would appear that changes in teachers' attitude and a better understanding of students' educational needs and perception of plagiarism may provide the means to enable HEls to help students to avoid plagiarism in a more effective way.
\end{abstract}

\section{Introduction}

Plagiarism is becoming an important issue of increasing concern in our societies these days. Views and attitudes on plagiarism, however, differ from culture to culture as shown by the study of Carroll (2008) on foreign students going to the UK, and by

The International Journal for Educational Integrity is available online at:

http://www.ojs.unisa.edu.au/journals/index.php//JEl/

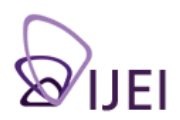


the study of Sutherland-Smith (2008) on international students going to Australia. Plagiarism is an interdisciplinary issue that combines psychological and sociological aspects with ethical and legal ones, and has a national and cultural context (Sutherland-Smith, 2005). Although most of the Western European countries are sensitive to plagiarism there are countries, like those in Eastern Europe, where plagiarism is not considered to be a big problem (Foltýnek \& Čech, 2012). As a consequence plagiarism is most often judged on the basis of what is considered correct in the Western societies without taking into account any country specific cultural roots (Pennycook, 1996).

Several studies have already been published on students' and teachers' perception of plagiarism. Risquez, O'Dwyer and Ledwith (2013) found that although students declare a personal interest in plagiarism and consider plagiarising to be generally bad and punishable, they fail to distinguish specific cases of plagiarism. In fact, in most cases, students are unable to judge whether there is a case of plagiarism or not. Yeo (2007) made a study with six different cases. Three of them were quite similar to ones examined in this paper and shows that students are able to recognise clear cases of plagiarism, but often fail when additional circumstances are mentioned. In addition, neither students nor teachers appear to be consistent when expressing themselves as to what they consider as plagiarism. In fact, as Gu and Brooks (2008) have shown, students may actually express their teachers' views rather than their own, thus making it difficult to pinpoint any differences in students' views. Furthermore, many students may omit citing and referencing because they are not able to recognise where it is required to do so (Risquez et al., 2013), thus committing plagiarism unintentionally. Regarding teachers, they usually do not punish plagiarism intentionally. Most often they regard plagiarism as a failure on their part, and either they do not look for cases of plagiarism or they choose to ignore them (SutherlandSmith, 2005).

The majority of students are thought to become aware of plagiarism before or when they start their bachelor degree studies. However, at that time, some students do not know how to cite and to reference literature sources correctly, since these skills are taught much later (Foltýnek \& Čech, 2012). One would, therefore, expect teachers to be the ones who will take the opportunity to enable students to develop their skills of writing without plagiarising. However, this may not be possible if there are differences between teachers' and students' perception/awareness of (a) what constitutes academic writing and the reasons that students resort to plagiarism, (b) the type of penalties imposed in cases of plagiarism, and (c) the institutional policies and procedures that deal with plagiarism. This study was aimed at identifying if teachers and students from HEls of several EU countries differ significantly in their perception and awareness of the above. Understanding such difference may enable the development of a European-wide plagiarism prevention approach through education, with teachers as the protagonists.

\section{Material and methods}

We have examined the answers to a survey conducted under the IPPHEAE project with a focus on plagiarism policies, procedures, prevention and penalties at various $\mathrm{HEls}$ in EU countries across Europe. In total, 2,588 and 572 questionnaires from students and teachers respectively were collected, namely from UK, Poland, Lithuania, Czech Republic, Cyprus, Slovakia, Germany, Greece, Bulgaria, Portugal, Austria, France, Finland, Malta and Ireland. All collected questionaries were used in this study.

For the purpose of this paper, only some of the questions and statements were analysed. To make it clearer, they were divided into four areas of concern within which the students' and teachers' responses were analysed accordingly. Specifically, we compared the following areas: 
A. Training in techniques for scholarly academic writing.

- I have received/Students receive training in techniques for scholarly academic writing and anti-plagiarism issues.

- What do you/students find difficult about academic writing?

B. Plagiarism prevention.

- What leads students to decide to plagiarise?

- Assuming that $40 \%$ of a student's submission is from other sources and is copied into the student's work as described in (a-f) below, indicate your judgment on plagiarism.

a. Word for word with no quotations.

b. Word for word with no quotations, has correct references but no intext citations.

c. Word for word with no quotations, but has correct references and in-text citations.

d. With some words changed with no quotations, references or in-text citations.

e. With some words changed with no quotations, has correct references but no in-text citations.

f. With some words changed with no quotations, but has correct references and in-text citations.

C. Penalties for plagiarism.

- What would happen if a student at your institution was found guilty of plagiarism in their assignment or final project/dissertation?

D. Policies and procedures.

- $\quad$ This institution has policies and procedures for dealing with plagiarism.

- $\quad$ Plagiarism policies, procedures and penalties are available to students.

- $\quad$ Penalties for plagiarism are administered according to a standard formula.

- $\quad$ Student circumstances are taken into account when deciding penalties for plagiarism.

Results are reported as percentages. A two-sample t-test was used to determine whether there was a significant difference between the answers of teachers and students with respect to the percentage who chose a particular answer from each survey question. The analysis was done using the SPSS Statistics 21 programme. Results discussed as being significantly different are those which were significant at the 0.05 critical alpha level.

\section{Results and discussion}

Training in techniques for scholarly academic writing

The majority of EU students and teachers agreed $(>62 \%)$ that students receive training in techniques for scholarly academic writing and anti-plagiarism issues during their studies. There were differences between EU countries in the percentages of positive answers given. However, since the answers between teachers and students from the same HEl were in agreement, it became apparent that there are institutions in EU countries which do not provide students with any training on plagiarism.

The analysis of data on how students learn/get trained on academic writing that will enable them to avoid plagiarism (Figure 1) showed a student preference $(54 \%)$ for the web. This source of learning was underestimated by teachers who chose instead their own methods (i.e. class lectures and guidance notes), as the most preferred by students to help them avoid plagiarising. It would appear, therefore, that teachers 
would like students to get to know about plagiarism via classes, workshops and class notes, whereas students would rather get the information from the internet.

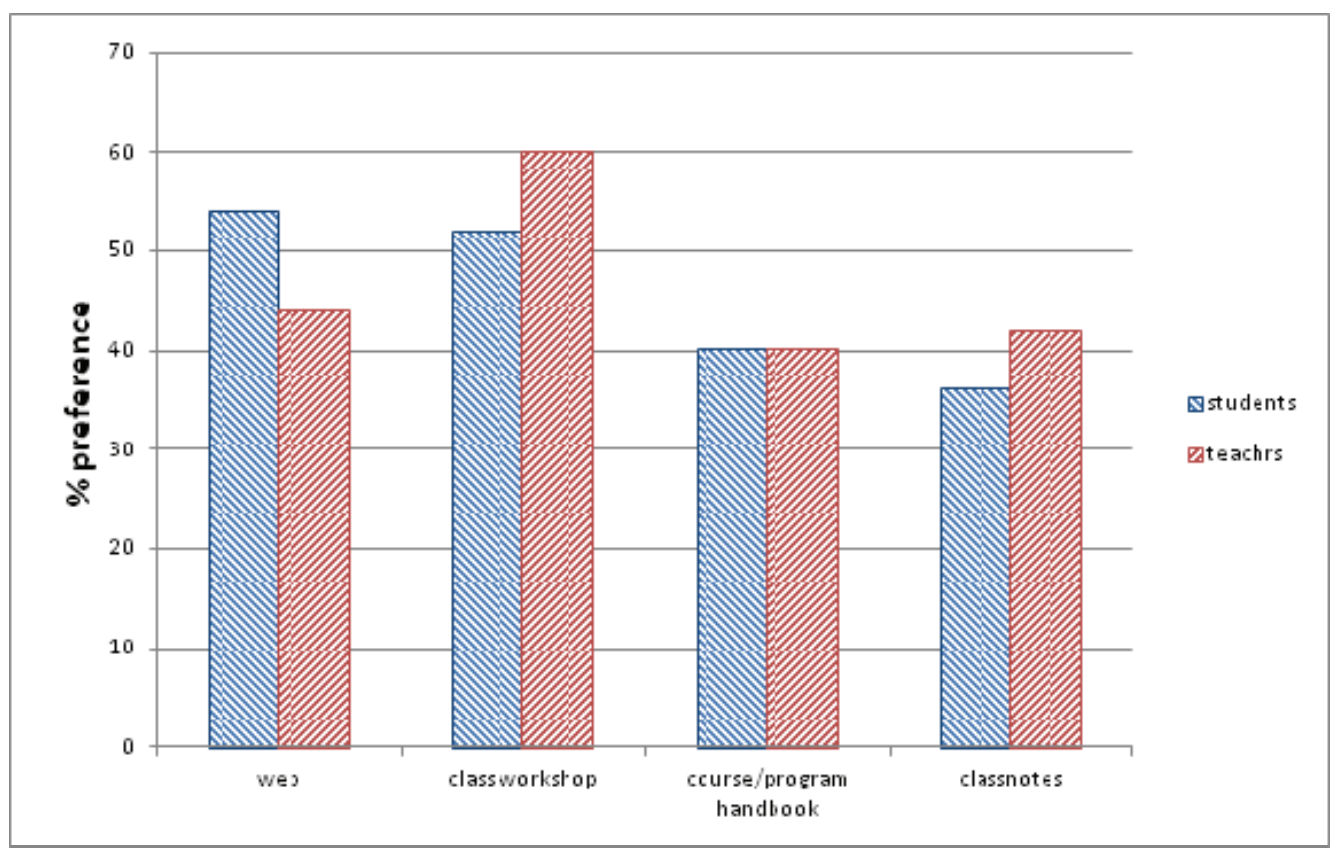

Figure 1. Differences in the preference for teaching and learning sources for educating students in academic writing

Similarly, when participants were asked to choose what students may find most difficult about academic writing, the majority of students chose different aspects to those considered by teachers as most difficult (Figure 2). For example, whereas the majority of students $(64 \%)$ indicated that finding a good quality source for reading material was the most difficult aspect of academic writing, the majority of teachers $(92 \%)$ thought that students have more difficulty in understanding the different referencing formats.

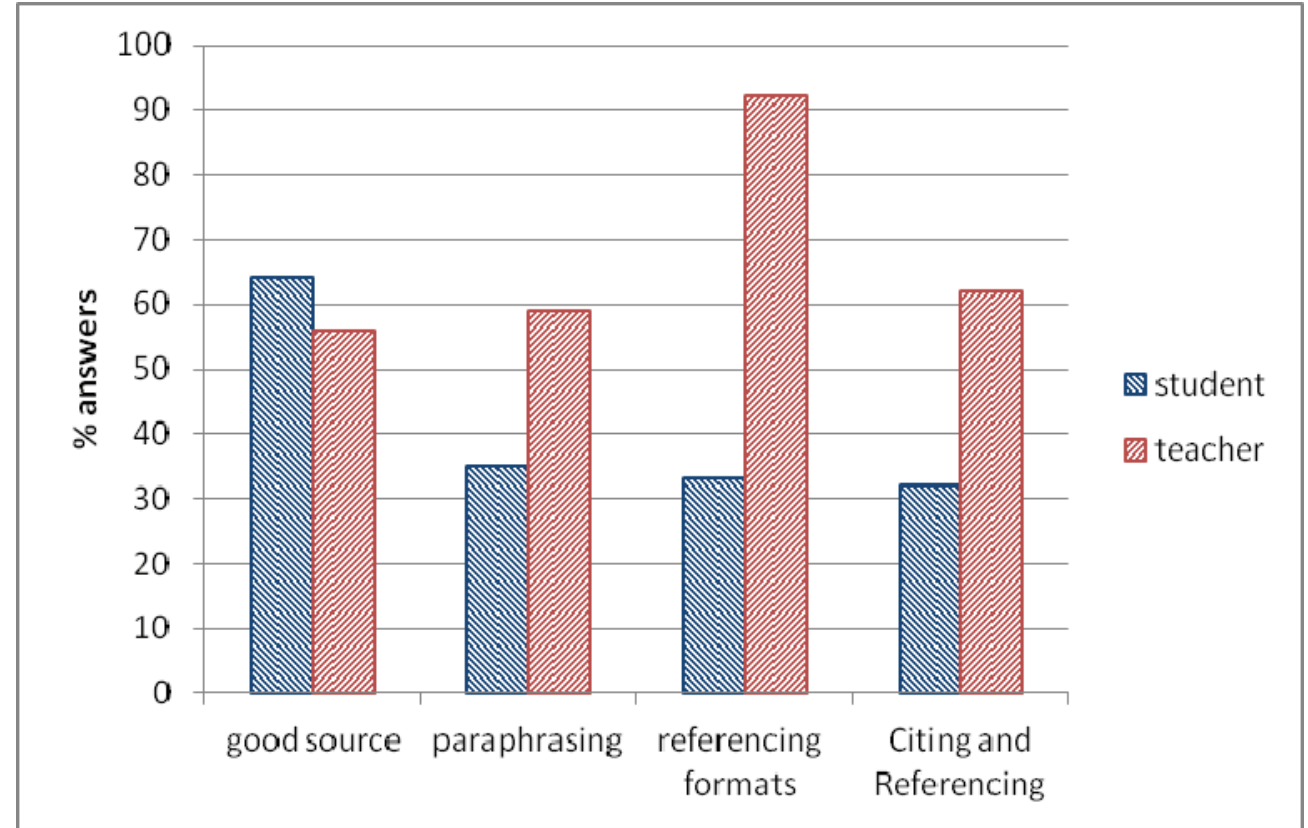

Figure 2. Differences in the perception of what students and teachers consider as difficult in academic writing. The differences in all cases were statistically significant (two sample t-test, $p<0.05$ ). 
As we can see, teachers giving an assignment to students would prefer to focus on the explanation of referencing formats and on citing and using references correctly. However, this is not what the students think that they need. They would rather prefer to be taught how to find good quality resources. Both of the above paradigms suggest that teachers need to pay greater attention to students in order to identify their needs and expectations in how to write academic work. Based on the above, one may then assume that if students received better training in academic writing they should be able to write assignments without having to resort to plagiarism. However, would training in academic writing alone be enough to prevent plagiarism?

\section{Plagiarism prevention}

In trying to prevent plagiarism effectively, one also needs to understand the reasons students plagiarise. Both teachers and students were given the same set of 21 reasons for students plagiarising and asked to choose the 10 most likely ones. When the data was analysed in terms of choice differences between teachers and students, it became apparent that teachers underscored a number of reasons that students consider as the cause for resorting to plagiarism. Furthermore, teachers overscored the importance of additional causes.

Table 1:

Most likely reasons for students plagiarising (all results were significant at $p<0.05$ (two sample t-test))

\begin{tabular}{|l|c|c|}
\hline Reasons & $\begin{array}{c}\text { Chosen by } \\
\text { teachers (\%) }\end{array}$ & $\begin{array}{c}\text { Chosen by } \\
\text { students (\%) }\end{array}$ \\
\hline It is easy to cut and paste from the internet. & 83 & 67 \\
\hline Plagiarism is not seen as wrong. & 53 & 32 \\
\hline They think the lecturer will not care. & 46 & 32 \\
\hline Their reading comprehension skills are weak. & 39 & 26 \\
\hline They don't see the difference between group work and & 28 \\
\hline collusion. & 52 & 64 \\
\hline They run out of time. & 24 & 41 \\
\hline They are unable to cope with the workload. & 20 & 30 \\
\hline They think their written work is not good enough. & 15 & 28 \\
\hline They feel the task is completely beyond their ability. & 10 & 23 \\
\hline Assignments tasks are too difficult or not understood. & & \\
\hline
\end{tabular}

As shown in Table 1, both teachers and students showed similar trends in the order of what they considered as important reasons for plagiarising. These results are in agreement with those reported by DeVoss and Rosati (2002). According to the teachers' opinions, students plagiarise mostly because they are lazy, lack reading comprehension skills or they think that nobody will care or be able to recognise that plagiarism is wrong (Table 1, upper part). However, according to students' choices, it appears that running out of time, inability to cope with the workload and deadlines, and a sense of insecurity are the most likely reasons for students to plagiarise (Table 1 , lower part).

There was a greater difference in opinions regarding the notion that "Plagiarism is not seen as wrong" by the students. Apparently students know that it is wrong to 
plagiarise but there are other reasons, which lead them to do so. One of these is "They are unable to cope with the workload" which is highly underscored by teachers.

The apparent problem with time management as indicated from these results may explain why students choose to resort to cutting and pasting from the internet when writing an assignment, as indicated by the most popular reason for plagiarising that was chosen by students (Table 1 ). The underscoring of the above reasons by teachers would suggest that teachers might differ in their perception of the difficulty of a task/assignment given to students. Looking at the two reasons, i.e., "The task is beyond their ability" and "Tasks are too difficult or not understood" (Table 1, lower part), chosen by about $25 \%$ of the students but only by $10-15 \%$ of teachers, one could conclude that if assignments/tasks were made easier, students may be able to complete these without resorting to plagiarism. However, as McDowell and Brown (1998) suggest, this may not be the case since teachers and students judge the difficulty of assignment tasks differently. The present results suggest that a better approach in preventing students from resorting to plagiarism may be getting students to better manage their time, providing them with sources for background reading to help students understand the assigned task, become more motivated and less afraid to deal with it.

However, students may still plagiarise if there is no consensus between teachers and students on what constitutes plagiarising. In order to check how close the teachers' and students' perception are of plagiarism, we have examined the verdicts (judgements: serious plagiarism, plagiarism, not sure, not plagiarism) given by students and teachers for a hypothetical case when $40 \%$ of a student's work is copied with varied use of citations and references (see a-f, in Materials and methods). The first three cases contain the statement "Word for word with no quotations" and the next three "With some words changed". Within each case additional definitions for plagiarism are: "No references, no in-text citations", "Correct references, but no in-text citations", and "Correct references and in-text citations". Figures 3 and 4 show the differences in the percentages of teachers' and students' verdict of plagiarism in each case.

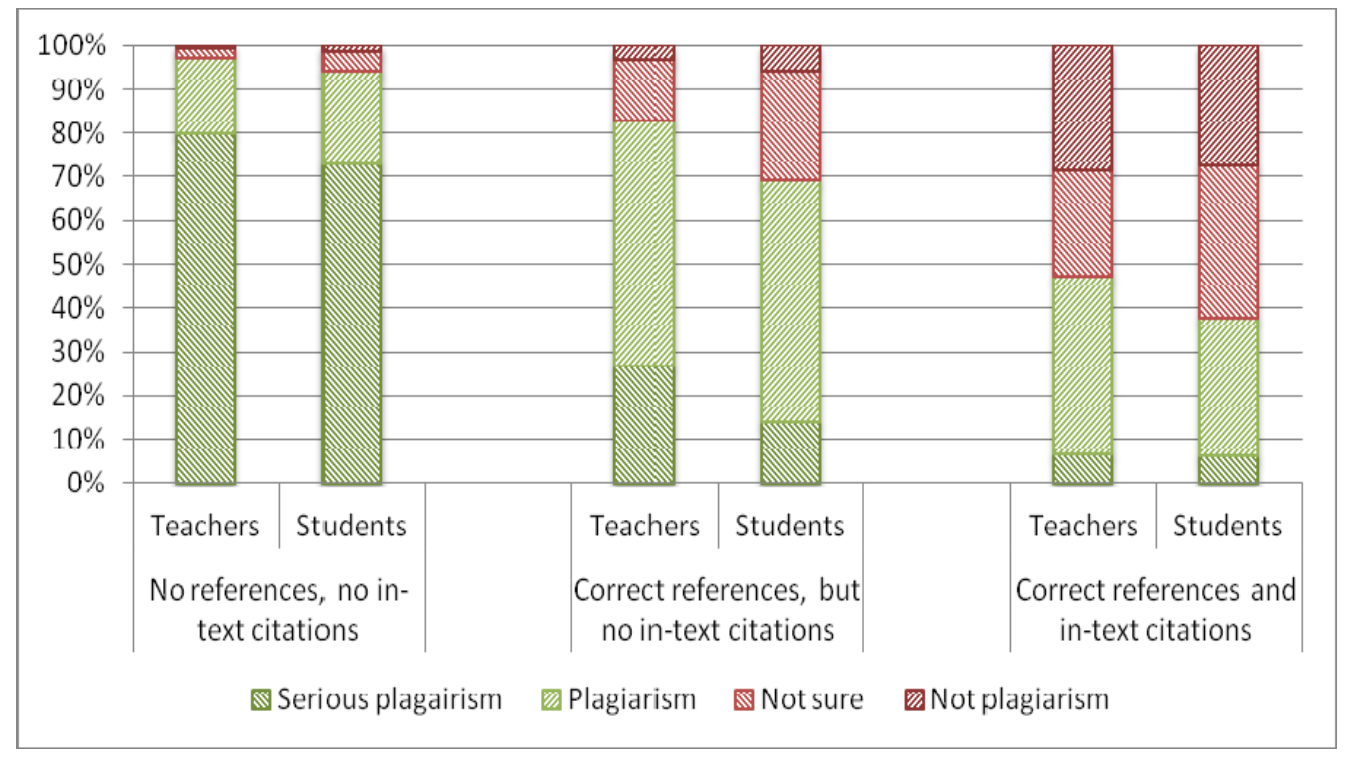

Figure 3. Teachers' and students' verdicts on plagiarism, when $40 \%$ of student's work is copied word for word with no quotations. The differences in all cases were statistically significant (two sample t-test, $p<0.05$ ) except case 1 , "not plagiarism"; case 2, "plagiarism"; case 3, "serious plagiarism" and "not plagiarism". 


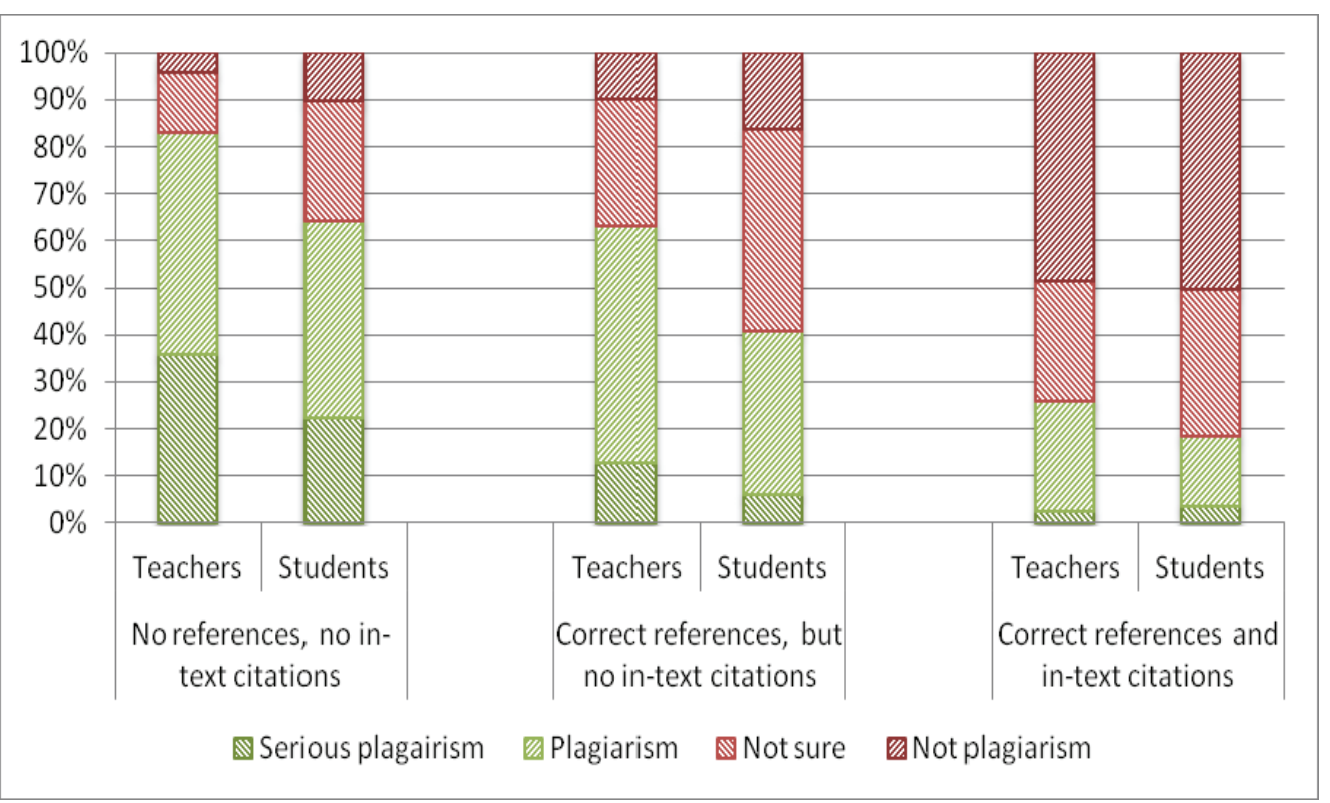

Figure 4. Teachers' and students' verdicts on plagiarism, when $40 \%$ of student's work is copied with no quotations, some words are changed. The differences in all cases were statistically significant (two sample t-test, $p<0.05$ ) except the third case - items "serious plagiarism" and "not plagiarism".

More teachers than students gave a verdict of plagiarism when $40 \%$ of the assignment was copied. This was also the case when no references and in-text citations were used in agreement with the observations of Yeo (2007). The use of intext citations and references appear to reduce both students' and to a lesser extent teachers' percentage of verdicts of plagiarism. It is also of interest to note that in all cases, a certain percentage of teachers and a much greater percentage of students were not sure or gave a judgement of no plagiarism. The percentage of such responses increased when references and in-text citations were used. Furthermore, when some words in the $40 \%$ copied part of the assignment were changed, the percentage of teachers and students who gave a verdict of plagiarism or serious plagiarism dropped. The above results indicate that both students and to a greater extent teachers are aware of plagiarism but are less likely to give a verdict of plagiarising if quotations and/or references and in-text citation are used. This is most likely to be also the case if less than $40 \%$ of an assignment is copied and suggests that there is a need for a detailed definition of plagiarism that will not leave gaps in its perception by students or teachers.

\section{Penalties for plagiarism}

A major topic, which is related to students' and teachers' awareness and perception of plagiarism, is whether plagiarism should be penalised and what should such a penalty involve. Both students and teachers were given a choice of 13 possible penalties and were asked to indicate the penalty known to them to be imposed if plagiarism were to be detected in a student's assignment or in a student's (undergraduate or graduate master's) final project (dissertation).

Analysis of the data using a two-pair t-test for percentages showed that there were no differences in the percentage of teachers and students (range 49-50\%) who chose a particular penalty to be imposed for plagiarising in an assignment. The descending preference order of penalties chosen was the same for both teachers and students: "zero mark for the work" followed by "request to rewrite", and then by "verbal warning". There was less of an agreement between students' and teachers' responses for penalties given for plagiarism in a final project or dissertation. The penalty "zero mark 
for the work" was the most popular choice for students whereas almost $50 \%$ of the teachers chose "request to rewrite". More students (33\% vs. $24 \%$; $p=0,0006)$ chose "fail the module or subject" and this was the case for other forms of punishment like "expose student to school community" (17\% vs. $8 \%$; p $\quad 0)$, "suspend payment of student grant" ( $17 \%$ vs. $7 \%$; p 0 ), "fail the whole program or degree" ( $31 \%$ vs. $22 \%$; $p=0,033)$ and "suspended from the institution" (29\% vs. $20 \% ; p \quad 0)$. The broader range of penalties chosen and the differences between students and teachers most likely reflect the more lenient stance that teachers may take as a result of shared responsibilities in supervising student projects and having to consider the reputation of their Department/School of their Institution.

\section{Policies and procedures}

Both students and teachers were asked whether their institutions had policies and procedures for dealing with plagiarism, about their availability and ways of administering these. Results were analysed in terms of "Yes/No" and "Not sure" answers and are shown in Table 2. As shown, more than $50 \%$ of students and teachers were aware of the existence of policies and procedures for dealing with plagiarism at their institutions. As compared to teachers, however, a lot more students were not sure about them or how they were administered. These results suggest that HEls in EU may need better ways of making faculty and students aware of policies/ procedures on plagiarism. One such way may be for teachers to undertake to communicate such information to students to the benefit of both.

Table 2:

Students' and teachers' views of policies and procedures on plagiarism, at their institutions

\begin{tabular}{|l|c|c|c|c|c|c|}
\hline & \multicolumn{3}{|c|}{ Students } & \multicolumn{3}{c|}{ Teachers } \\
\hline & Yes & $\begin{array}{c}\text { Not } \\
\text { sure }\end{array}$ & No & Yes & $\begin{array}{c}\text { Not } \\
\text { sure }\end{array}$ & No \\
\hline $\begin{array}{l}\text { This institution has policies and } \\
\text { procedures for dealing with plagiarism. }\end{array}$ & $68 \%$ & $24 \%$ & $5 \%$ & $75 \%$ & $11 \%$ & $13 \%$ \\
\hline $\begin{array}{l}\text { Plagiarism policies, procedures and } \\
\text { penalties are available to students. }\end{array}$ & $54 \%$ & $33 \%$ & $10 \%$ & $60 \%$ & $27 \%$ & $13 \%$ \\
\hline $\begin{array}{l}\text { Penalties for plagiarism are } \\
\text { administered according to a standard } \\
\text { formula. }\end{array}$ & $39 \%$ & $49 \%$ & $9 \%$ & $50 \%$ & $31 \%$ & $18 \%$ \\
\hline $\begin{array}{l}\text { Student circumstances are taken into } \\
\text { account when deciding penalties for } \\
\text { plagiarism. }\end{array}$ & $22 \%$ & $54 \%$ & $20 \%$ & $35 \%$ & $45 \%$ & $16 \%$ \\
\hline
\end{tabular}

All percentages in Table 2 were proved to be statistically significant at the 0.05 alpha level using the t-test.

\section{Conclusion}

This preliminary exploration of only a part of the data collected from the IPPHEAE survey has identified several interesting facts that may have an impact on plagiarism prevention policies and in designing anti-plagiarism courses for students:

- $\quad$ students are informed about plagiarism primarily from the web and not through lecturing or from teachers' guidance notes

- $\quad$ the most difficult aspect of academic writing for students is finding a good quality source for information retrieval rather than referencing

- most teachers misunderstand students' reasons for resorting to plagiarism

- $\quad$ more teachers than students give a verdict of plagiarism for work that is plagiarised 
- $\quad$ teachers' and students' opinions on plagiarism policies/procedures and on penalties do not agree.

Taking into account the above may help teachers to be more effective in trying to educate students about plagiarism, and HEls in implementing their policies on plagiarism by using a more fair approach in dealing with and penalising students who plagiarise. Considering that there were differences in the number of teacher and student participants between the various EU countries, with the highest number of responses coming from the Czech Republic, it is possible that the results obtained from this analysis are biased. An analysis at national level may identify greater differences for some of the EU countries participating. This is only a preliminary analysis of some of the data collected, and further comparisons using a country by country approach and even an institution by institution approach may be needed for the observed differences to be used as guides for a more holistic approach in dealing with plagiarism in different parts of the EU.

\section{Acknowledgements}

The research was funded by the project Impact of Policies for Plagiarism in Higher Education Across Europe (510321-LLP-1-2010-1-UK-ERASMUS-EMHE).

Authors are very grateful to all the project consortium partners for their cooperation in survey design and data collection: Coventry University (UK), Technical University of Lodz (Poland), Aleksandras Stulginkis University (Lithuania), University of Nicosia (Cyprus).

\section{References}

Carroll, J. (2008). Assessment issues for international students and for teachers of international students. In R. Atfield \& P. Kemp (Eds.), Enhancing Internationalisation in Business and Management Hospitality Leisure Sport Tourism. Newbury: Threshold Press. Available from http:// www.heacademy.ac.uk/assets/hlst/documents/case_studies/carroll.pdf

DeVoss, D., \& Rosati, A. C. (2002). It wasn't me, was it? Plagiarism and the web. Computers and Composition, 19(2), 191-203.

Foltýnek, T., \& Čech, F. (2012). Attitude to plagiarism in different European countries. Acta Universitatis Agriculturae et Silviculturae Mendelianae Brunensis, vol. LX, no. 7, 71-80.

Gu, Q., \& Brooks, J. (2008). Beyond the accusation of plagiarism. System, 36(3), 337 -352 .

McDowell, L., \& Brown, S. (1998). Assessing students: Cheating and plagiarism. MARCET, University of Northumbria at Newcastle.

Pennycook, A. (1996). Borrowing others' words: Text, ownership, memory, and plagiarism. TESOL Quarterly, 30, 201-230. DOI: 10.2307/3588141

Risquez, A., O'Dwyer, M., \& Ledwith, A. (2013). "Thou shalt not plagiarise": From selfreported views to recognition and avoidance of plagiarism. Assessment \& Evaluation in Higher Education, 38(1), 34-43.

Sutherland-Smith, W. (2005). Pandora's box: Academic perceptions of student plagiarism in writing. Journal of English for Academic Purposes, 4(1), 83-95.

Sutherland-Smith. W. (2008). Plagiarism, the internet, and student learning: Improving academic integrity. New York: Taylor and Francis.

Yeo, S. (2007). First year university science and engineering students' understanding of plagiarism. Higher Education Research \& Development, 36(2). DOI 10.1080/07294360701310813 
Copyright statement

Copyright ( 2013 Authors listed on page 1: The authors grant to the IPPHEAE 2013 Conference organisers and educational non-profit institutions a non-exclusive licence to use this document for personal use and in courses of instruction provided that the article is used in full and this copyright statement is reproduced. Any other usage is prohibited without the express permission of the authors.

\section{About the authors}

Tomáš Foltýnek is a research assistant at the Department of Informatics, Faulty of Business and Economics, Mendel University in Brno, Czech Republic. Tomáš teaches namely algorithms, theoretical informatics and related topics. He was a member of a team designing and implementing the plagiarism detection tool for Mendel University information system.

Jiři Rybička is an Associate Professor at the Department of Informatics, Faulty of Business and Economics, Mendel University in Brno, Czech Republic. Jiř́ teaches namely programming techniques and bachelor thesis seminars. He is a member of a team developing the University information system and an expert in typography and typesetting.

Catherine Demoliou is Professor of Biochemistry at the Department of Life and Health Sciences, School of Sciences, University of Nicosia, Cyprus. Besides Biochemistry, she has wide experience with setting up policies and procedures for plagiarism and academic dishonesty as a former Dean, member of University of Nicosia QA-Committee, University Accreditation Interim Committee and others. 